\title{
P04-45. Characterization of the plasma cell repertoire in acute HIV-I infection (AHI)
}

L Liao*1, X Chen $^{1}$, A Dixon ${ }^{1}$, S Munshaw ${ }^{1}$, M Moody $^{1}$, R Zhang ${ }^{1}$, A Nagel ${ }^{1}$, A Foulger ${ }^{1}$, K Derosa ${ }^{1}$, R Parks ${ }^{1}$, M Mcparland ${ }^{1}$, J Whitesides ${ }^{1}$, D Marshall ${ }^{1}$, J Amos ${ }^{1}$, Y Yang ${ }^{1}$, F Gao ${ }^{1}$, T Shea ${ }^{2}$, D Margolis ${ }^{2}$, G Shaw ${ }^{3}$, M Markowitz ${ }^{4}$, T Denny ${ }^{1}$, G Kelsoe ${ }^{1}$, G Tomaras ${ }^{1}$, T Kepler $^{1}$ and B Haynes ${ }^{1}$

Address: ${ }^{1}$ Human Vaccine Institute, Duke University, Durham, NC, USA, ${ }^{2}$ University of North Carolina-Chapel Hill, Chapel Hill, NC, USA, ${ }^{3}$ University of Alabama at Birmingham, Birmingham, AL, USA and ${ }^{4}$ Aaron Diamond AIDS Research Center, Rockefeller University, New York, USA

* Corresponding author

from AIDS Vaccine 2009

Paris, France. 19-22 October 2009

Published: 22 October 2009

Retrovirology 2009, 6(Suppl 3):P73 doi:10.1 186/1742-4690-6-S3-P73

This abstract is available from: http://www.retrovirology.com/content/6/S3/P73

(C) 2009 Liao et al; licensee BioMed Central Ltd.

\section{Background}

Analysis of immunoglobulin (Ig) $V H$ and $V L$ genes derived from sorted single $\mathrm{B}$ cells is a powerful technology for definition of Ig repertoires to viral infections. The purpose of this study was to characterize the Ig repertoire of plasma cells/plasmablasts (PCs) in subjects early on after HIV transmission.

\section{Methods}

Blood PCs from three AHI subjects obtained approximately 17, 20 and 30 days after HIV-1 transmission were sorted into 96-well plates for amplification of $V H$ and $V L$ genes by RT/PCR. The isolated $\mathrm{VH}$ and $\mathrm{VL}$ genes were expressed as recombinant IgG1 mAbs in 293T cells by transfection using linear Ig expression cassettes, The specificity of produced mAbs was determined by ELISA and luminex bead immunoassays against a panel of HIV-1 and non-HIV-1 antigens.

\section{Results}

The number of circulating plasma cells ranged from $1.9 \%$ to $21.0 \%$. When HIV antibodies were detected in subject plasma, only antibodies to Env gp41 were present. A total of $787 \mathrm{Ig} V H$ and $V L$ gene pairs were expressed as whole IgG1 antibodies. HIV-specific antibodies accounted for only $6.5 \%$ of expressed antibodies (range $1.7 \%$ to $19 \%$ ).
All HIV-1 antibodies were against gp41 with no antibodies reacting with any other HIV-1 proteins. Non-HIV-1 antibodies identified from AHI PCs included those against influenza $(0.6 \%)$, tetanus toxoid $(1.9 \%)$, cardiolipin $(0.8 \%)$, Cryptococcus $(0.9 \%)$, Candida $(0.5 \%)$, Hep2 epithelial cells $(5.2 \%)$, gut flora (1.7\%), lipid A (0.6\%) and unknown $(79.3 \%)$.

\section{Conclusion}

While the initial plasma cell response to influenza vaccination was primarily antigen specific against hemagglutinin, the initial plasma cell response to HIV-1 was primarily polyclonal with massive expansion of non-HIV antibodies. The extraordinary degree of polyclonal B cell activation as early as 17 days after transmission is in part responsible for the ineffective initial antibody response to transmitted HIV. 